\title{
O COMPORTAMENTO NAS EQUIPES E SEUS IMPACTOS NO AMBIENTE LABORAL: UM ESTUDO DE CASO
}

\author{
TEAMWORK BEHAVIOR AND ITS CONSEQUENCES IN A WORKING \\ ENVIRONMENT: A CASE STUDY
}

\author{
Robson Luiz Montanari ${ }^{1}$ \\ Luiz Alberto Pilatti ${ }^{2}$
}

Recebido em 25/09/2011

Aceito em 10/12/2011

\begin{abstract}
RESUMO
$\mathrm{O}$ artigo apresenta um estudo de caso em equipes de uma empresa de médio porte, prestadora de serviços, objetivando identificar comportamentos presentes no trabalho em equipe e possíveis impactos no ambiente laboral das mesmas. O método de pesquisa utilizado foi o estudo de caso, e os preceitos de Yin (2001) foram adaptados para o caso. Os procedimentos metodológicos foram permeados por entrevistas, observações não participantes e a aplicação de dois questionários, propostos por Moscovici (2003). Os resultados indicaram que a criação de algumas regras para as equipes em estudo não foram suficientes para garantir comportamentos conducentes ao trabalho coletivo. Comportamentos indesejáveis ao ambiente laboral das equipes permearam o ambiente produtivo, interferindo negativamente no modo de funcionamento das mesmas. Concluiu-se que, à medida que as equipes tiverem maturidade suficiente, as mesmas passarão a prestar atenção no modo de funcionamento do grupo e os comportamentos indesejáveis tenderão a diminuir, possibilitando maximizar a performance da equipe.
\end{abstract}

Palavras-Chave: Equipes. Trabalho em equipe. Reuniões de equipes.

\begin{abstract}
The article shows a case study of teamworks of a medium-sized service provider company in order to identify group work behavior and its consequences in a working environment. The research method used was the case study itself, and the Yin (2001) precepts were adapted to the case. The methodological procedures were permeated by interviews, non-participant observations and the application of
\end{abstract}

\footnotetext{
${ }^{1}$ Mestre em Engenharia da Produção pela Universidade Tecnológica Federal do Paraná - Campus Ponta Grossa, Paraná. Especialista em Gestão Industrial com ênfase em Conhecimento e Inovação pela Universidade Tecnológica Federal do Paraná - Campus Ponta Grossa, e em Gestão Estratégica de Pessoas e Negócios pela Fae Business School. E-mail: prof_robson@terra.com.br

${ }^{2}$ Doutor em Educação Física pela Universidade Estadual de Campinas, São Paulo. Atua como Professor da Universidade Tecnológica Federal do Paraná Campus Ponta Grossa, Paraná, onde está vinculado aos cursos de graduação em Engenharia de Produção e Programas de Pós-Graduação em Engenharia de Produção (PPGEP) e Ensino de Ciência e Tecnologia (PPGECT). E-mail: <lapilatti@utfpr.edu.br>
} 
two questionnaires proposed by Moscovici (2003). The results indicated that the establishment of a few rules for the teamworks being studied were not enough to ensure acceptable behavior during group work. Undesirable teamwork behavior in a working environment affected the productive environment, interfering negatively in the way the teams worked. It was concluded that, as teamworks become more mature, they will start paying more attention to group work, and undesirable behaviors are likely to decrease, maximizing their performances.

Keywords: Teamwork. Group work. Teamwork meetings.

\section{Introdução}

O ambiente laboral moderno já não se assemelha ao de algumas décadas atrás. Forças inelutáveis como a globalização, a tecnologia, o crescimento e declínio em setores de trabalho criaram uma nova Era: a Era do Conhecimento. O trabalho nesta Era, que é desenvolvido pelos trabalhadores do conhecimento, está fortemente ligado ao desempenho organizacional que, por sua vez, está intimamente associado ao conhecimento e ao poder inovativo empresarial.

A percepção da importância do conhecimento na Era do Conhecimento deve-se ao fato de que as atividades das organizações estão intimamente associadas ao capital humano, que representa um ativo estratégico responsável pela criação do conhecimento pessoal e organizacional. Para Claver-Cortês et al. (2007), as empresas cada vez mais adotam projetos organizacionais flexíveis, estruturas com menos níveis hierárquicos, a fim permitir o diálogo entre equipes, incentivando deste modo a aprendizagem coletiva para gerar novos conhecimentos.

Em decorrência da necessidade de respostas rápidas, os recursos humanos tiveram seus papéis redesenhados dentro de um cenário absolutamente novo. O emprego tem deslocado o foco do processo de profissionalização do fazer para o saber fazer; de um trabalho individual em um posto específico para o trabalho coletivo. Para Sacomano e Escrivão Filho (2000), a abertura dos mercados para a concorrência internacional exigiu das empresas brasileiras, tanto de capital nacional como internacional, esforços significativos para atingir patamares competitivos. Bejarano (2006), ao analisar a questão, destaca que a busca incessante por melhorias na performance organizacional é uma realidade no atual ambiente de trabalho, pois as organizações são atualmente movidas pela competitividade da economia globalizada e pela crescente necessidade do aumento de produtividade.

Quando o assunto é produtividade, enfatiza Bejarano (2006), as empresas estão buscando cada vez mais investir em equipes como parte da sua estrutura organizacional. Drucker (2001) faz esta constatação e destaca que o trabalho em equipe não é bom nem desejável, é um fato. Sempre que as pessoas trabalham ou jogam em conjunto, elas o fazem em equipe. Outros autores, como Chang (1999) e Katzenbach e Smith (2001), defendem que as equipes são fundamentais para o desempenho empresarial diante de um cenário de mudanças e podem ser utilizadas como resposta às mudanças organizacionais.

Tendo o trabalho em equipe como uma constante e uma realidade nas empresas da Era do Conhecimento, levanta-se um questionamento: que comportamentos estão presentes no ambiente laboral das equipes? O presente artigo tem como objetivo identificar os comportamentos presentes nas equipes e seus impactos no ambiente laboral das mesmas.

A partir do trabalho de sete equipes de uma empresa de médio porte, prestadora de serviços, que utiliza equipes no setor operacional, a pesquisa faz um estudo de caso buscando um entendimento mais abrangente sobre o comportamento nas equipes no ambiente produtivo. $\mathrm{O}$ artigo apresenta referencial teórico, procedimentos metodológicos adotados, resultados obtidos e conclusões do caso em exame. 


\section{Referencial Teórico}

As equipes podem representar um fator fundamental na busca de vantagens competitivas, pois os "esforços individuais resultam em um desempenho, queé maior quea soma das contribuições de cada um dos indivíduos" (ROBBINS, 2001, p. 262). Bejarano e Pilatti (2008) delimitaram diversos fatores externos que dificultam o trabalho em equipe, relacionando-os a três elementos propostos como essenciais na implementação de equipes: estrutura, estratégia e seleção. Chang (1999) e Bejarano et al. (2005b) apresentaram fatores internos esclarecer funções e responsabilidades, solucionar discordâncias, tomar decisões objetivas -, que também dificultam o desempenho das equipes. Além destes fatores externos e internos, outro fator a considerar é enfatizado por Schwartz (2007), que associa o desempenho das pessoas a quatro estados da energia, como mostra a Figura 1:

Figura 1- Matriz de energia

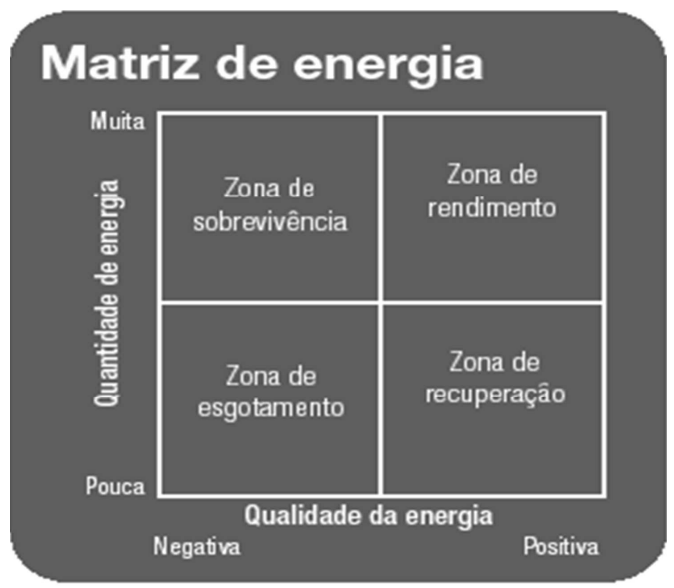

Fonte: SCHWARTZ (2007, p. 3)

Segundo Schwartz (2007), quando uma pessoa consegue colocar em prática todo seu potencial ela está entusiasmada, confiante, satisfeita, alegre e produtiva, e esses sentimentos descrevem a "zona de rendimento". Contudo, afirma Schwartz (2007) que poucas pessoas se mantêm nela a maior parte do tempo. Para ele as pessoas costumam se localizar na "zona de sobrevivência", onde mesmo com sensações de irritação e frustração, realizam o trabalho. A permanência na "zona de sobrevivência" por muito tempo consumirá grande parte da energia e acabará levando a pessoa à "zona de esgotamento", na qual será muito difícil trabalhar. O último quadrante, a "zona de recuperação", está associada aos momentos de relaxamento, que são poucos durante o trabalho. Assim se faz necessário alternar ciclos de gasto de energia com outros de renovação, como pequenas pausas durante o trabalho e as férias. (SCHWARTZ, 2007).

Karakowsky et al. (2004) destacaram percepções e influências entre homens e mulheres trabalhando em equipes. Homens e mulheres podem alterar suas percepções na equipe baseando-se, por exemplo, na qualidade de esforços da sua equipe. Montanari (2008) aponta que diferentes comportamentos dos membros da equipe trazem impactos na maneira como a mesma trabalha e isso influencia o desempenho dela. Em linhas gerais, a performance das equipes está relacionada a inúmeros fatores que são interdependentes no trabalho coletivo. $\mathrm{Na}$ visão de Bejarano et al. (2005a), conduzir equipes na obtenção de melhor desempenho não é fácil, mesmo quando se podem reunir os melhores talentos individuais. Robbins e Finley (1997, p. 57) compartilham desta concepção e inferem que as pessoas em equipe são "como as pessoas em qualquer outro lugar", ou seja, "têm seus altos e baixos".

Nesta perspectiva, um fator a considerar e que está intimamente associado ao ambiente laboral das equipes é a maturidade. A maturidade é perspectivada por Hersey e Blanchard (1986) e Katzenbach e Smith (1994) como um fator de graduação e classificação do desempenho das pessoas em equipe. Para Hersey e Blanchard (1986 p.187), "a maturidade é a capacidade e a disposição das pessoas de assumir a responsabilidade de dirigir seu próprio comportamento, devendo estas variáveis de maturidade ser consideradas somente em relação a uma tarefa específica a ser realizada". Em linhas gerais, o individuo com maturidade alta tem disposição para assumir responsabilidades em função da sua capacidade de dirigir seu próprio comportamento. $\mathrm{O}$ que já não ocorre com as pessoas que apresentam maturidade baixa, pois as mesmas não mostram tal capacidade.

Na visão de Katzenbach e Smith (1994), a maturidade está associada ao modo de funcionamento das equipes, que podem ser classificadas de acordo com a sua maturidade em uma das cinco posições: 
1. "Pseudo-equipe": este tipo de grupo pode definir um trabalho a se fazer, mas não se preocupa com o desempenho coletivo, nem tenta consegui-lo. As interações dos membros inibem o desempenho individual, sem produzir nenhum ganho coletivo apreciável.

2. "Grupo de trabalho": os membros desse grupo não veem nenhuma razão para se transformarem numa equipe. Podem partilhar informações entre si, porém responsabilidades, objetivos, por exemplo, pertencem a cada individuo.

3. "Equipe potencial": este grupo quer produzir um trabalho conjunto. No entanto, os membros precisam de esclarecimentos e orientações sobre sua finalidade e objetivos.

4. "Equipe real": uma equipe real compõe-se de poucas pessoas, mas com habilidades complementares e comprometidas umas com as outras através de missão e objetivos comuns. Os membros passam a confiar uns nos outros.

5. "Equipe de alta performance": este grupo atende a todos as condições de equipe real e há um comprometimento profundo entre seus membros com o intuito de crescimento pessoal de cada um.

A Figura 2 ilustra a curva de desempenho proposta por Katzenbach e Smith (1994). Na proposta é evidenciada uma sequência evolutiva dos grupos de trabalho até as equipes de alta performance.

Figura 2 - Curva de desempenho

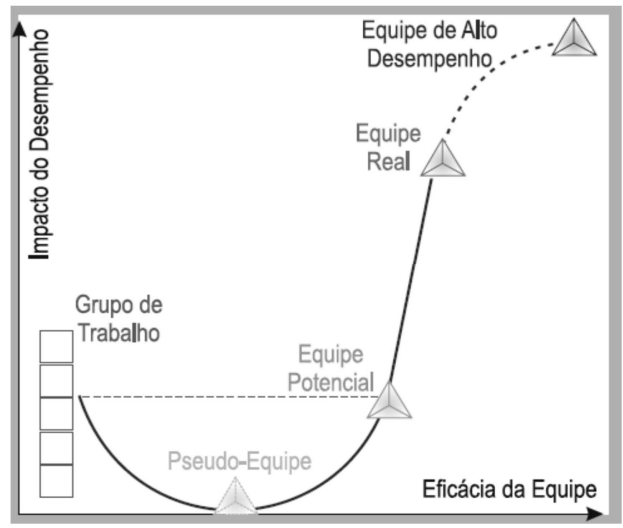

Fonte: KATZENBACH e SMITH (1994, p. 85)

A sequência evolutiva apresentada por Katzenbach e Smith (1994) mostra que o modo de funcionamento do grupo precisa seguir "[...] uma disciplina simples, porém contínua, para alcançar bom desempenho" (KATZENBACH, 1999, p. 57). Uma equipe é um grupo de pessoas com aptidões complementares e comprometidas com um objetivo comum, assim, o seu modo de funcionamento é responsável pela sua performance.

Drucker (2001) distingue três tipos de equipes, também pelo modo de funcionamento, considerando que qualquer grupo que trabalhe junto constitui uma equipe pela associação de valores, como compartilhamento, cooperação e ajuda mútua. Para o autor, um grupo de pessoas trabalhando juntas constitui uma equipe. Considera que as equipes se diferem no comportamento que exigem, naquilo que fazem melhor e no que não podem, ou seja, cada equipe "joga" de uma maneira e apresenta dificuldade para mudar a sua tática. Assim, distinguem-se três tipos de equipes:

1. os membros têm posições fixas; eles atuam na equipe, mas não em equipe, por exemplo, uma equipe cirúrgica, uma equipe de beisebol, ou uma linha de montagem;

2. os membros têm posições fixas, mas atuam em equipe, por exemplo, um time de futebol;

3. os membros têm posições principais em vez de fixas. Eles devem "cobrir" seus companheiros de equipe, ajustando-se quando necessário, por exemplo, duplas de tênis ou conjunto de jazz.

Em contrapartida, Salomão (1999) considera que o que singulariza uma equipe são resultados comuns obtidos por interatividade. A equipe, então, é caracterizada quando pessoas se juntam e oferecem suas competências, conjugando esforços para fazerem coisas que são da responsabilidade do conjunto, mesmo que haja uma "chefia" que se responsabilize por elas. Esta visão também é compartilhada por outros autores - Fisher et al. (1997), Katzenbach (1999), Sacomano Neto e Escrivão Filho (2000), Katzenbach e Smith (2001) e Moscovici (2003) -, que relacionam o trabalho em equipe a objetivos comuns, ao compartilhamento de competências e de esforços. $\mathrm{O}$ fato de trabalharem em conjunto, o modo de funcionamento, não dá aos grupos, independente das posições que seus membros ocupem (fixas ou não), o status de "equipe", contrariando o pensamento de Drucker (2001).

O raciocínio de Drucker (2001) proporciona o entendimento de uma situação que nem sempre é 
suficientemente clara, pois nem todos os grupos têm a mesma finalidade. Em linhas gerais, não existem justificativas para uma equipe de futebol "jogar" como uma dupla de tênis. Na primeira equipe existe a necessidade de trabalho interdependente, os "jogadores" dependem uns dos outros, enquanto na segunda, não. E também não existem justificativas para uma equipe de beisebol "jogar" como uma equipe de futebol, pois na primeira equipe o trabalho é na equipe e não em equipe.

Em se tratando de equipes no ambiente produtivo, algumas necessidades são citadas e continuam sendo observadas ao longo dos anos por inúmeros autores - Goldbarg (1995), Parker (1995), Chang (1999), Katzenbach e Smith (2001), Aleixo (2003) e Bejarano (2006) - como indispensáveis ao trabalho das equipes. Uma delas diz respeito às reuniões das equipes. "Há várias crenças que depreciam o enfoque de equipe na empresa" (MOSCOVICI, 2003, p. 21). Para algumas empresas as equipes não produzem melhor do que indivíduos bem capacitados e motivados e "perdem muito tempo em reuniões estéreis, em discussões irrelevantes e em sessões de queixas e lamentações" (MOSCOVICI, 2003, p. 21). Não obstante, no atual território empresarial, as reuniões passam a ser muito importantes para o processo de decisão, pois as constantes mudanças e transformações pedem frequentes ajustes às organizações.

Para as equipes as reuniões são fundamentais, pois as mesmas coordenam e dão suporte a ações e mudanças. Na visão de Aleixo (2003), sem reuniões as equipes não sobrevivem, pois são nessas ocasiões que os conflitos e os problemas de comunicação aparecem. É nas reuniões, também, que se oportunizam as trocas de informações, ampliando a comunicação e, consequentemente, o fortalecimento do comprometimento para desenvolver habilidades e preservar a experiência adquirida. Reunião rápida e eficiente não é o objetivo principal, o desejado é o entusiasmo, a criatividade e participação de todos no processo de solução de problemas em debates abertos, enfatiza Goldbard (1995).

Para Parker (1995), as reuniões eficazes precisam começar no horário, de um gerenciador das discussões, com capacidades de estimular as opiniões, esclarecer ideias, sintetizar e não perder o foco no assunto. Chang (1999) ressalta que as reuniões ineficientes apresentam falta de pauta, pouca participação, discussões longas e sem sentido, poucas decisões ou absolutamente nenhuma decisão. Um conjunto de regras nas reuniões, seguindo os preceitos de Parker (1995), torna-se fundamental para a coletividade da equipe.

A maneira de como a equipe prepara e conduz as reuniões faz uma considerável diferença no ambiente produtivo, mencionam Katzenbach e Smith (2001). Diferentes abordagens produzem diferentes comportamentos e, por consequência, resultados distintos. Assim, as equipes devem concentrar muita atenção em dois padrões. O primeiro diz respeito ao uso eficiente do tempo. Agendas, assuntos e prazos devem ser definidos com antecedência. $\mathrm{O}$ segundo padrão é em relação aos objetivos. Quando não existe um objetivo, as discussões se perdem e raramente decisões são tomadas.

Para Katzenbach e Smith (2001, p. 83), é necessário "planejar reuniões e sessões de trabalho que se ajustem a diferentes tarefas e desempenhos obrigatórios". São necessárias diferentes reuniões para diferentes tipos de trabalho. Os autores relacionam duas etapas que podem ajudar equipes a planejar e conduzir reuniões mais coerentes para qualquer tarefa a ser realizada. São elas:

1. Definir o objetivo da reunião em termos de desempenho: as reuniões devem ter objetivos claros diretamente relacionados aos resultados exigidos.

2. Preparar duas listas de problemas e assuntos: No decorrer das reuniões, pequenos grupos tratam de assuntos diferentes, assim o desempenho é otimizado.

Estas etapas podem auxiliar no desempenho das reuniões das equipes e no ambiente de trabalho das mesmas, contudo deve-se articular a visão de trabalho à missão dos grupos. As equipes obtêm maior êxito quando discutem as principais influências que pretendem exercer e quando transformam essas discussões em frases ganham direcionamento, proporcionado pela articulação do trabalho e objetivos da equipe. (KATZENBACH; SMITH, 2001).

As discussões de autores - Goldbarg (1995), Parker (1995), Chang (1999), Katzenbach e Smith (2001), Aleixo (2003) e Bejarano (2006) - a respeito do trabalho em equipe no ambiente produtivo apontam que as equipes podem ganhar um direcionamento 
melhor no trabalho quando possuem um conjunto de regras que garantam o funcionamento da equipe no ambiente laboral. Os padrões adotados pelas equipes podem fazer uma diferença substancial na performance da equipe e da organização.

\section{Procedimentos Metodológicos}

Para obtenção de conhecimento científico faz-se necessário conhecer as construções mentais que possibilitem alcançar os objetivos almejados. Na visão de Gil (1999, p. 27), isto significa a determinação do método que "é o caminho para se chegar a determinado fim". O método de pesquisa utilizado é o estudo de caso que, segundo preceitos de Yin (2001), trata-se de um método a ser utilizado quando se desenvolve uma investigação empírica de um fenômeno dentro de seu contexto da vida real, explorando as condições entre o fenômeno e o contexto em que este está inserido. $\mathrm{O}$ contexto estudado se passa em uma empresa de médio porte, prestadora de serviços no ramo de transporte de passageiros, que utiliza a gestão baseada em equipes no setor operacional.

Os procedimentos prescritos por Yin (2001), adaptados ao caso em exame, foram seguidos. Em termos práticos, observaram-se as seguintes etapas: a) elaboração de entrevista semiestruturada, composta de questões abertas e com roteiro para sua condução; b) entrevista; c) definição dos questionários para aplicação nos membros das equipes; d) definição da população; e) observações não participantes; f) aplicação dos questionários; e g) análise dos dados.

A coleta dos dados aconteceu no período de maio a junho de 2006, a partir de quatro entrevistas, observações não participantes e a aplicação de dois questionários. Os questionários são compostos de alternativas e, baseados na experiência de cada membro com sua equipe, o participante escolhe a resposta que melhor reflete seu grau de concordância ou discordância, escolhendo uma nota em uma escala social de 1 a 7 . Em relação a cada questão, a nota maior significa "concordo plenamente" e a nota menor "discordo totalmente".

A entrevista semiestruturada foi aplicada a quatro gerentes da empresa. O objetivo da entrevista com um dos entrevistados foi de caráter exploratório; com os demais o objetivo foi verificar os comportamentos presentes nas equipes e seus impactos.
Os entrevistados receberam a sigla D (declarantes) e foram numerados com algarismos arábicos a fim de se preservar as suas identidades. Buscando melhorar a interpretação das respostas e dos registros na entrevista, utilizou-se, com a autorização dos entrevistados, um gravador. As gravações foram transcritas ipsis litteris com autorização dos entrevistados.

A população de respondentes foi composta de um universo de 77 membros de equipes da empresa em estudo. Todos os membros das equipes responderam aos dois questionários e pontuaram cada fator. Para cada um dos fatores foi então calculada a média aritmética simples e o desvio padrão, que caracterizaram o grau de importância médio atribuído a cada fator, a dispersão e a uniformidade de graus atribuídos pelos respondentes.

Na sequência, os questionários "O que Acontece no Grupo" e "Avaliação da Reunião", propostos por Moscovici (2003), foram aplicados. Juntamente com a aplicação dos questionários foram feitas observações de caráter não participante. Os membros das equipes responderam aos questionários identificando somente a equipe a que pertenciam. As equipes receberam a sigla $E$ (equipe) e foram numeradas com algarismos arábicos. Em seguida, os respondentes depositaram os questionários respondidos em urnas a fim de assegurar sigilo sobre suas opiniões e, também, estabelecer um clima de confiança e empatia. (TRIVIÑOS, 1987).

Para análise dos dados obtidos utilizou-se a técnica de triangulação sugerida por Triviños (1987), que, em linhas gerais, consiste no emprego de diferentes evidências para busca de uma resposta mais aprofundada. Segundo Yin (2001, p. 121), "várias fontes de evidências fornecem essencialmente várias avaliações do mesmo fenômeno". Os procedimentos tiveram a intenção de aumentar a compreensão dos dados para análise e conclusões dos resultados no caso em exame.

\section{Resultados e Análises}

As experiências pessoais e profissionais têm uma participação fundamental na maturidade das pessoas, pois interagem ativamente com a capacidade de cada um em assumir responsabilidades e atuar no estabelecimento de novos comportamentos. À medida que as pessoas mudam o comportamento, 
adaptam-se a outros novos comportamentos, transformando-se a si mesmos e interagindo com o ambiente laboral.

Durante as observações não participantes no ambiente laboral das equipes em estudo observou-se o comportamento das mesmas e de seus integrantes, o que possibilitou a identificação do modo de funcionamento dos grupos. Os preceitos teóricos de Drucker (2001) possibilitaram a caracterização dos grupos no tipo: os membros possuem posições fixas. Em linhas gerais, os integrantes dos grupos atuam na equipe, mas não em equipe. Os membros das equipes em estudo desempenham atividades no ambiente laboral individualmente, mas que contribuem para o resultado coletivo. Esta constatação é melhor percebida nas entrevistas, que denotam o modo de funcionamento: "aqui na empresa o trabalho é individual, mas o resultado positivo só pode ser alcançado pela contribuição de todos os trabalhos individuais" (D2). "Na verdade nossos colaboradores trabalham sozinhos, mas fazem parte de uma equipe [...]" (D4).

O raciocínio de Drucker (2001) proporciona o entendimento sobre o modo de funcionamento e a finalidade das equipes na empresa em estudo. Em linhas gerais, não há necessidade de trabalho interdependente, os "jogadores" das equipes não dependem uns dos outros, pois o trabalho da equipe não acontece em equipe. Para o declarante D3 o modo de funcionamento das equipes atende às necessidades da empresa: "as equipes têm papel importante na prestação de serviços da empresa, pois conseguem resolver problemas e melhorar os serviços prestados".

As observações não participantes nas reuniões das equipes e a entrevista exploratória complementaram o entendimento sobre o funcionamento das equipes que estão estruturadas da seguinte forma:

1. Um líder, escolhido de forma democrática pelos membros da equipe.

2. Um facilitador determinado pela empresa para auxiliar nas reuniões.

3. Missão das equipes.

4. Regras de comportamento entre os membros, como: não chegar atrasado às reuniões, participar até o seu término, contribuição nas discussões, evitar conversas paralelas, seja sobre o assunto ou fora dele, ter liberdade de expressão, sem censuras, e somente uma pessoa fala de cada vez.
5. Reuniões periódicas, em média de uma a duas por mês, para o que se definiu uma agenda pelo facilitador e os membros das equipes. Regras para as reuniões também foram criadas, como o uso de pauta e registro em ata das questões levantadas e decisões tomadas.

As sete equipes em estudo foram compostas tendo como critério de seleção um balanceamento entre os que já possuíam algumas habilidades necessárias e os que precisavam desenvolvê-las. Nas reuniões acontece o compartilhamento das informações e experiências vivenciadas no ambiente produtivo. A partir da troca e discussão dessas informações, os membros das equipes tomam decisões que mudam os processos de trabalho. Em seguida, as equipes registram em atas as alterações sofridas nos processos e compartilham entre as demais equipes para disseminar e auxiliar novos processos de decisões (D1).

Esses resultados refletem a perspectiva de autores - Goldbarg (1995), Parker (1995), Chang (1999), Katzenbach e Smith (2001), Aleixo (2003) a respeito dos procedimentos a serem adotados para reuniões de equipes: agenda de reuniões, missão, pautas e registros das discussões, e possuírem um moderador ou facilitador para conduzi-las, a fim de evitar as discussões sem sentido. Entretanto, em pesquisa com o questionário "O que Acontece no Grupo", proposto por Moscovici (2003), observou-se a presença de comportamentos indesejáveis ao ambiente laboral de reuniões, como mostra a Tabela 1: 
Tabela 1 - Comportamento nas equipes

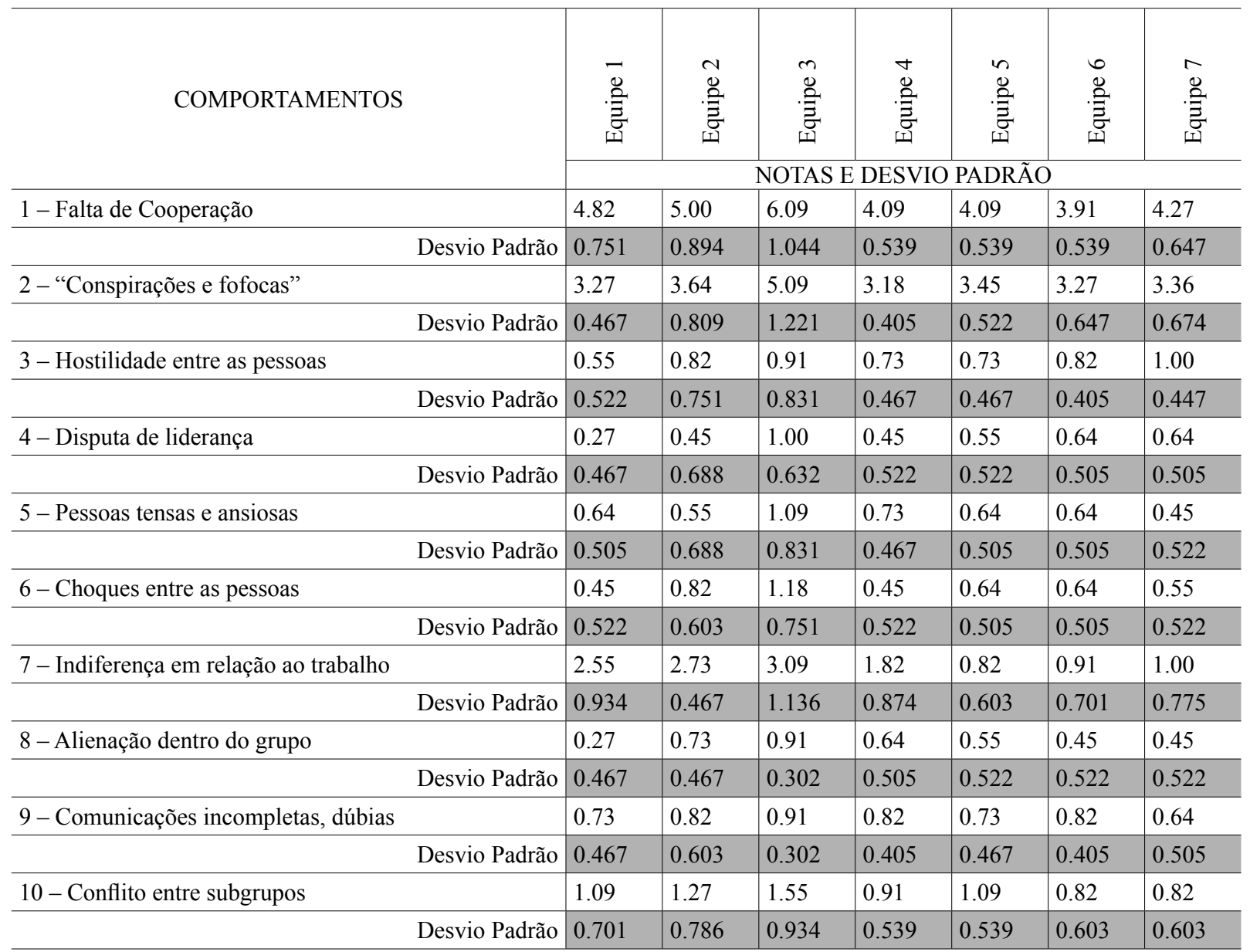

Fonte: os autores.

Os resultados da Tabela 1 mostram que comportamentos como falta de cooperação (1), conspirações e fofocas (2) e indiferença em relação ao trabalho (7) são os que mais acontecem nas equipes. $\mathrm{Na}$ equipe 3 , os resultados nestes três itens apresentam as maiores notas e os maiores desvio padrão, indicando a divergência de opiniões e a existência de comportamentos que podem estar prejudicando as reuniões e, por consequência, o trabalho em equipe. Segundo Katzenbach e Smith (2001), a condução das reuniões pode produzir diferentes abordagens entre os membros das equipes e influenciar nos comportamentos.

Moscovici (2003) ressalta que a falta de recursos para atender a todas as necessidades humanas gera conflitos entre os membros. A trajetória de um grupo é acompanhada de constantes conflitos que acontecem em virtude do crescimento e desenvolvimento do grupo e as suas consequências poderão ser positivas ou negativas, dependendo do modo como os conflitos são administrados é administrado.

Os resultados apresentados na Tabela 1 podem estar associados à "matriz de energia" sugerida por Schwartz (2007). Quando as pessoas conseguem colocar em prática todo seu potencial, elas estão entusiasmadas e conseguem ser mais produtivas. O que já não ocorre com as pessoas que estão em uma "zona de esgotamento", cuja produtividade fica bastante comprometida pelo consumo de energia no ambiente laboral.

Procurando analisar as reuniões das equipes pesquisou-se, a partir do questionário "Avaliação da Reunião", proposto por Moscovici (2003), saber como os membros das equipes em estudo avaliam as reuniões da equipe a que pertencem. Os resultados obtidos foram: 
Tabela 2 - Avaliação da reunião

\begin{tabular}{|c|c|c|c|c|c|c|c|c|}
\hline AVALIAÇÃO DA REUNIÃO & $\begin{array}{l}\text { ESCALA } \\
\text { LIKERT }\end{array}$ & 芯 & $\begin{array}{l}\sim \\
\stackrel{0}{\Xi} \\
\stackrel{\Xi}{I}\end{array}$ & 永 & 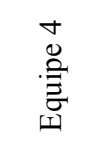 & 哽 & $\begin{array}{l}0 \\
\mathscr{0} \\
\stackrel{\Xi}{\Xi} \\
\text { İ }\end{array}$ & 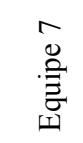 \\
\hline & & \multicolumn{7}{|c|}{ NOTAS E DESVIO PADRÃO } \\
\hline $\begin{array}{l}\text { 1-Suas opiniões foram solicitadas e/ou } \\
\text { levadas em consideração }\end{array}$ & \multirow{2}{*}{$\begin{array}{l}\text { 1-Nunca } \\
\text { 7-Sempre }\end{array}$} & 6.18 & 6.36 & 5.82 & 6.73 & 6.00 & 6.64 & 6.64 \\
\hline Desvio Padrão & & 0.751 & 0.674 & 0.751 & 0.467 & 0.447 & 0.505 & 0.505 \\
\hline 2-A quantidade de sua participação foi & \multirow{2}{*}{$\begin{array}{l}\text { 1-Insatisfatória } \\
\text { 7-Satisfatória }\end{array}$} & 6.36 & 6.55 & 6.00 & 6.27 & 6.27 & 6.36 & 6.55 \\
\hline Desvio Padrão & & 0.674 & 0.522 & 0.632 & 0.647 & 0.647 & 0.505 & 0.522 \\
\hline $\begin{array}{l}\text { 3-Sua possibilidade de influenciar nos } \\
\text { resultados foi }\end{array}$ & \multirow{2}{*}{$\begin{array}{l}\text { 1-Nenhuma } \\
\text { 7-Significativa }\end{array}$} & 6.55 & 6.45 & 6.27 & 6.45 & 6.45 & 6.45 & 6.45 \\
\hline Desvio Padrão & & 0.688 & 0.522 & 0.647 & 0.688 & 0.688 & 0.522 & 0.522 \\
\hline 4-Em relação à decisão final você se acha & \multirow{2}{*}{$\begin{array}{l}\text { 1-Sem responsabilidade } \\
\text { 7-Responsável }\end{array}$} & 6.45 & 6.36 & 6.00 & 6.55 & 6.73 & 6.55 & 6.64 \\
\hline Desvio Padrão & & 0.688 & 0.674 & 1.789 & 0.688 & 0.467 & 0.688 & 0.674 \\
\hline 5-Em relação à reunião você se sentiu & \multirow{2}{*}{$\begin{array}{l}\text { 1-Frustrado } \\
\text { 7-Satisfeito }\end{array}$} & 6.27 & 5.91 & 5.73 & 6.55 & 6.55 & 6.73 & 6.45 \\
\hline Desvio Padrão & & 0.905 & 0.831 & 1.679 & 0.522 & 0.522 & 0.467 & 0.522 \\
\hline $\begin{array}{l}\text { 6-Você se sente disposto a defender a } \\
\text { decisão tomada }\end{array}$ & \multirow{2}{*}{$\begin{array}{l}\text { 1-De maneira nenhuma } \\
\text { 7-Irrestritamente }\end{array}$} & 6.36 & 6.64 & 6.36 & 6.64 & 6.55 & 6.73 & 6.82 \\
\hline Desvio Padrão & & 0.809 & 0.809 & 1.286 & 0.674 & 0.522 & 0.647 & 0.405 \\
\hline $\begin{array}{l}\text { 7-Quanto à qualidade da decisão tomada } \\
\text { você achou }\end{array}$ & \multirow{2}{*}{$\begin{array}{l}\text { 1-Péssima } \\
\text { 7-Excelente }\end{array}$} & 6.45 & 6.64 & 5.82 & 6.00 & 6.36 & 6.45 & 6.45 \\
\hline Desvio Padrão & & 0.522 & 0.505 & 0.405 & 0.632 & 0.674 & 0.522 & 0.688 \\
\hline
\end{tabular}

Fonte: os autores.

Observa-se na Tabela 2 que as equipes 1,2 , 4,5 e 6 não apresentam tanta disparidade nos resultados. Porém, a equipe 3 evidencia resultados, em todos os itens, abaixo da média das outras equipes e possui o maior desvio padrão nos itens 4,5 e 6 , caracterizando a existência de possíveis problemas e de opiniões divergentes dentro da equipe. Um fato interessante nos resultados da equipe 3 é o de que, mesmo tendo procedimentos iguais aos das demais equipes durante as reuniões, como constatado com o declarante D1 e nas observações não participantes, mostra resultados divergentes quando comparada às demais equipes.

A equipe 3 indica a presença de problemas nas reuniões e no trabalho, pois existem membros que se sentiram menos e outros mais frustrados em relação à reunião, as reuniões não estão deixando todos satisfeitos. Ao contrário das outras equipes, nas quais a nota é maior e o desvio padrão menor. Os resultados da equipe 3 mostram que as reuniões podem se tornar um problema, as equipes e a empresa poderão sofrer com a falta de responsabilidade e comprometimento para com as decisões tomadas. Cabe à empresa, através do programa de implantação e desenvolvimento das equipes, resolver com as equipes os problemas que, de alguma forma, podem estar comprometendo o desempenho das equipes nas reuniões.

A partir dos resultados até agora expostos um questionamento é bastante relevante: as equipes na empresa em estudo podem ser consideradas equipes? A equipe é caracterizada quando pessoas reúnem esforços para fazerem coisas que são da responsabilidade do grupo, preconiza Salomão (1999). Esta perspectiva é compartilhado por outros autores - Fisher et al. (1997), Katzenbach (1999), Sacomano Neto e Escrivão Filho (2000), Katzenbach e Smith (2001) e Moscovici (2003) - que relacionam o trabalho em equipe a objetivos comuns, a comprometimento mútuo e responsabilidades compartilhadas. Neste sentido, os resultados da equipe 3 , por exemplo, evidenciam que o grupo está longe de trabalhar como uma equipe.

Tendo como base os resultados das Tabelas 1 e 2, denota-se a existência de divergências nas respostas dadas pelos membros das equipes. Em todas as equipes existe a falta de cooperação, fofocas 
e indiferença ao trabalho (Tabela 1 - itens 1,2 e 7). Fica evidente na equipe 3 que alguns membros entendem que se doaram mais do outros (Tabela 2 item 1). Pode-se inferir, segundo Katzenbach e Smith (1994), que a equipe 3 é um tipo de grupo (Pseudoequipe) que não se preocupa com o desempenho coletivo e nem tenta consegui-lo.

Já as demais equipes, segundo Katzenbach e Smith (1994), são um tipo de grupo (Grupo de Trabalho) em que os membros não veem razão para se transformarem numa equipe, mas podem partilhar informações entre si. O que se percebe no item 2, da Tabela 2, é que a quantidade da participação dos membros nas reuniões foi satisfatória; no item 7 , da Tabela 2, o processo de comunicação se mostrou eficaz, e o item 1, da Tabela 2, mostrou a falta de cooperação.

Moscovici (2003, p. 05) relata que "não é fácil estabelecer parâmetros precisos, pois a equipe é um grupo com funcionamento qualificado". O modo de funcionamento do grupo exerce um papel importante pois, segundo Moscovici (2003), um grupo se desenvolve para funcionar como equipe quando passa a administrar seus próprios conflitos a partir de apaziguamento, negociação e resolução de problemas. Assim, o programa de implantação e desenvolvimento de equipes precisa contribuir no sentido de administrar os conflitos e problemas para facilitar a abertura para o diálogo, podendo então criar um clima favorável no ambiente laboral das equipes.

\section{Conclusões}

As reuniões são fundamentais no ambiente organizacional. Para as empresas com gestão baseadas em equipes as reuniões são indispensáveis. Neste sentido, as reuniões de equipes no ambiente produtivo merecem atenção especial pois, segundo Robbins e Finley (1997), muitas vezes a diversidade humana pode contribuir para o insucesso das equipes. Os resultados do presente estudo evidenciam esta necessidade. Problemas considerados pequenos ou comuns podem contribuir negativamente no funcionamento dos grupos. Os resultados apontam nas equipes em estudo a existência de membros que se sentem mais e outros menos responsáveis; que se sentem mais ou menos insatisfeitos; a falta de cooperação; e fofocas.
A criação de algumas regras como a pontualidade, a participação de um facilitador para coordenar as discussões e o uso de pauta e registro das reuniões se faz importante para o bom andamento das reuniões, como citam Parker (1995), Chang (1999), Katzenbach e Smith (2001) e Aleixo (2003). Entretanto, considerando os resultados obtidos, isto pode não ser suficiente. Conflitos ocorrem em qualquer forma de organização social. Esses fatos podem estar dependentes não só da abertura dos níveis gerenciais, mas também para a resolução dos mesmos a partir dos membros das equipes nas reuniões.

Pode-se inferir que as equipes precisam, segundo os preceitos de Moscovici (2003), prestar atenção no seu modo de funcionamento para que passem a trabalhar como uma equipe de alta performance, com pessoas comprometidas umas com as outras através de missão e objetivos comuns. Os comportamentos presentes nas reuniões empresariais de equipes (Tabela 1) trazem impactos no funcionamento das mesmas (Tabela 2). No entanto, à medida que esses comportamentos estiverem mais favoráveis ao trabalho das equipes no ambiente laboral, à medida que as equipes adquiram maior maturidade, o desempenho das equipes tende a ser melhorado e os impactos minimizados.

\section{REFERÊNCIAS}

ALEIXO, A. I. S. Procedimentos para implantar equipes. 2003. 111f. Dissertação (Mestrado em Engenharia da Produção) - Programa de Pós-Graduação em Engenharia de Produção, UFSC, Florianópolis.

BEJARANO, V. C. et al. Equipes e comunidades de prática como estruturas complementares na gestão do conhecimento organizacional. In: ENCONTRO NAC DE ENG DE PRODUÇÃO, XXV, 2005, Porto Alegre. Anais... Porto Alegre: ABEPRO, 2005a. p. 4851-4856.

Como Formar Equipes com Equilíbrio Ideal de Personalidades e Perfis Pessoais: a teoria e as ferramentas de Meredith Belbin. In: CONGRESSO BRASILEIRO DE ENSINO DE ENGENHARIA, XXXIII, 2005, Campina Grande. Anais... Campina Grande: Universidade Federal de Campina Grande-UFCG, 2005b. p. 1-12.

BEJARANO, V. C. Elementos essenciais à implementação de equipes: um estudo de caso da indústria de papel. 2006. 115f. Dissertação (Mestrado em Engenharia da Produção) Programa de Pós-Graduação em Engenharia de Produção, UTFPR, Ponta Grossa. 
BEJARANO, V. C.; PILATTI, L. A. Elementos Externos Essenciais à Implementação de Equipes: estudo de caso. Revista de Administração da Universidade de São Paulo. São Paulo, jan./fev./mar., v. 43, n. 1, p. 17-29, 2008.

CLAVER-CORTÉS, E. et al. Organizational Structure Features Supporting Knowledge Management Processes. Journal of Knowledge Management., v. 11, n. 4, p. 45-57, 2007.

CHANG, R. Y. Construindo uma equipe de sucesso. São Paulo: Futura, 1999.

DRUCKER, P. Administrando em tempos de grandes mudanças. 5. ed. São Paulo: Pioneira Thomson Learning, 2001.

FISHER, S. G. et al. Team or group? Managers' perceptions of the differences. Journal of Managerial Psychology., v. 12, n. 4, p. 232-242, 1997.

GIL, A. C. Métodos e técnicas de pesquisa social. São Paulo: Atlas, 1999.

GOLDBARG, M. A. Times: ferramenta eficaz para a qualidade total. São Paulo: Makron, 1995.

HERSEY, P.; BLANCHARD, K. H. Psicologia para administradores: as teorias e as técnicas da liderança situacional. São Paulo: EPU, 1986.

KARAKOWSKY, L. et al. Perceptions of Team Performance: the impact of group composition and task-based cues. Journal of Managerial Psychology. v. 19. n. 5. p. 506-525. 2004.

KATZENBACH, J. R. A Disciplina das equipes. HSMManagement. São Paulo, n. 17, nov-dez, p. 56-60, 1999.

.; SMITH, D. K. A força e o poder das equipes. São Paulo: Makron, 1994.

Equipes de alta performance: conceitos, princípios e técnicas para potencializar o desempenho das equipes. 6. ed. Rio de Janeiro: Campus, 2001.

MONTANARI, R. L. Os homens e as equipes de trabalho no ambiente produtivo. 2008. 187f. Dissertação (Mestrado em Engenharia da Produção) - Programa de Pós-Graduação em Engenharia de Produção, UTFPR, Ponta Grossa.

MOSCOVICI, F. Equipes dão certo: a multiplicação do talento humano. 8. ed. Rio de Janeiro: José Olympio, 2003.

PARKER, G. M. O poder das equipes. Rio de Janeiro: Campus, 1995.

ROBBINS, S. P. Administração: mudanças e perspectivas. São Paulo: Saraiva, 2001.

ROBBINS, H.; FINLEY, M. Por que as equipes não funcionam? Rio de Janeiro: Campus, 1997.
SACOMANO, N. M.; ESCRIVAO FILHO, E. Estrutura organizacional e equipes de trabalho: estudo da mudança organizacional em quatro grandes empresas industriais. Gestão \& Produção, São Carlos, ago., v. 7, n. 2, p. 136-145, 2000.

SALOMÃO, M. A. Desenvolvimento de Equipes. In: BOOG, G. G. (Org.). Manual de treinamento e desenvolvimento. Associação Brasileira de Treinamento e Desenvolvimento. 3. ed. São Paulo: Makron Books, 1999. Cap. Desenvolvimento de Equipes. p. 507-532.

SCHWARTZ, T. A Energia dá a Partida. HSM-Management. São Paulo, n. 62, mai-jun, 2007.

TRIVINOS, A. Introdução à pesquisa em ciências sociais. São Paulo: Atlas, 1987.

YIN, R. K. Estudo de caso: planejamento e métodos. 2. ed. Porto Alegre: Bookman, 2001. 